\title{
A Portable Automatic Endpoint Detection System for Amplicons of Loop Mediated Isothermal Amplification on Microfluidic Compact Disk Platform
}

\author{
Shah Mukim Uddin 1,2, Fatimah Ibrahim 1,2,*, Abkar Ahmed Sayad 1,2, Aung Thiha 1,2,
} Koh Xiu Pei ${ }^{3}$, Mas S. Mohktar ${ }^{1,2}$, Uda Hashim ${ }^{4}$, Jongman Cho ${ }^{1,2,5}$ and Kwai Lin Thong ${ }^{2,3}$

1 Department of Biomedical Engineering, Faculty of Engineering, University of Malaya, 50603 Kuala Lumpur, Malaysia; E-Mails: shahmukim@gmail.com (S.M.U.); abkar8819@gmail.com (A.A.S.); aungthiha.bme@gmail.com (A.T.); mas_dayana@um.edu.my (M.S.M.); minerva@inje.ac.kr (J.C.)

2 Centre for Innovation in Medical Engineering (CIME), Faculty of Engineering, University of Malaya, 50603 Kuala Lumpur, Malaysia; E-Mail: thongk1@um.edu.my

3 Microbiology Unit, Institute of Biological Sciences, Faculty of Science, University of Malaya 50603 Kuala Lumpur, Malaysia; E-Mail: xp_527@yahoo.com

4 Institute of Nano Electronic Engineering (INEE), Universiti Malaysia Perlis, 01000 Kangar, Perlis, Malaysia; E-Mail: uda@unimap.edu.my

5 Department of Biomedical Engineering, Inje University, Gimhae 621-749, South Korea

* Author to whom correspondence should be addressed; E-Mail: fatimah@um.edu.my; Tel.: +603-7967-6818; Fax: +603-7967-6878.

Academic Editor: Stephane Evoy

Received: 16 December 2014 / Accepted: 28 January 2015 / Published: 5 March 2015

\begin{abstract}
In recent years, many improvements have been made in foodborne pathogen detection methods to reduce the impact of food contamination. Several rapid methods have been developed with biosensor devices to improve the way of performing pathogen detection. This paper presents an automated endpoint detection system for amplicons generated by loop mediated isothermal amplification (LAMP) on a microfluidic compact disk platform. The developed detection system utilizes a monochromatic ultraviolet (UV) emitter for excitation of fluorescent labeled LAMP amplicons and a color sensor to detect the emitted florescence from target. Then it processes the sensor output and displays the detection results on liquid crystal display (LCD). The sensitivity test has been performed with detection limit up to $2.5 \times 10^{-3} \mathrm{ng} / \mu \mathrm{L}$ with different DNA concentrations of Salmonella
\end{abstract}


bacteria. This system allows a rapid and automatic endpoint detection which could lead to the development of a point-of-care diagnosis device for foodborne pathogens detection in a resource-limited environment.

Keywords: pathogen; Salmonella; food safety; diagnosis; LAMP; multiplexed detection; endpoint detection system; microfluidics; compact disc; lab-on-a-CD

\section{Introduction}

Illnesses and deaths caused by foodborne microbial pathogens have received major attention worldwide. Hence, food safety is a serious public health issue. In 2013, Foodborne Diseases Active Surveillance Network (FoodNet) reported 19,056 cases of infections, 4200 hospitalizations, and 80 deaths in 10 U.S. sites (affecting approximately $15 \%$ of the U.S. population) due to foodborne diseases [1]. Failure to detect foodborne pathogens in contaminated food may not only lead to far-reaching consequences on human health but also causes a large economic burden on the food industry. Research on rapid and reliable method of foodborne pathogen detection is still on going.

Conventional methods available for the detection and identification of microbial pathogenic agents are based on selective microbiological media to isolate the viable bacterial cells present in food [2,3]. As these media depend on the ability of the organisms to multiply to become visible colonies, it requires 2-3 days to have probable results and up to 5-7 days for confirmation [3-6]. Moreover, it is labor intensive and cumbersome as the analysis of samples require several steps e.g., culture medium preparation, inoculation of plates and colony counting [2].

For sensitive detection of pathogens with automated or semi-automated instruments in near real time, several biosensors and bio-based methods have recently been developed. These include bioluminescence sensors [2], Surface Plasmon Resonance (SPR) sensors [6-8], electrochemical immunosensors [9], Fluorescence Resonance Energy Transfer (FRET) [5,10-12], piezoelectric biosensors [13] and cell based sensors [14-16]. In order to reduce analysis period and achieve confirmation results for detection, several methods like the Polymerase Chain Reaction (PCR) [17-20], immunoassay [21-23] and microarray [24] have been developed. However, these methods and techniques require complex manual steps, skilled personnel and high-end sophisticated equipment. These requirements limit the accessibility of these techniques especially in resource-poor areas. Besides, most centralized and modern laboratories are limited to large cities. Therefore, near-patient tests that utilize cheap and reliable Point of Care Test (POCT) devices have become increasingly important to provide an alternative rapid, sensitive, accurate and automated method for detection of foodborne pathogens.

Lab-on-a-Chip (LOC) device also called "Micro Total Analysis System" ( $\mu$ TAS) is a reliable choice as a POCT device. Miniaturized device size, low consumption of reagent and sample, precise microfluidic volume control, less manual handling errors and automated fast turn-around time for operation of biochemical assay enable the integration of all necessary processes and laboratory operations into a single chip $[25,26]$. These compact devices can analyze the samples at the point of need rather than in a centralized highly equipped laboratory. Various researches have been conducted on microfluidic chips for pathogens detection [27-32]. Easley et al. [29] reported a microfluidic genetic 
analysis system for detection of Bacillus anthracis by solid-phase extraction (SPE), PCR and microchip electrophoresis (ME) in less than $30 \mathrm{~min}$. Beyor et al. [30] developed a laboratory-on-a-chip system for the detection of Escherichia coli K12 and E. coli O157 integrating cell pre-concentration, purification, PCR and capillary electrophoretic (CE) analysis on one single platform. Even though steps for pathogen detection start from target separation to endpoint detection are integrated on a single chip, it requires complicated tube connections for pneumatic fluid control which limits the miniaturization of full system.

Comparing all the LOC platform, lab-on-a-CD platform has received significant attention for its potential to integrate all biochemical reactions onto a single disc-pattern microfluidic device and perform multiplexed operations using a single motor. It leads toward the development of microfluidic sample-to-answer systems or $\mu$ TAS in vitro diagnostics (IVD) [33,34]. The centrifugal, inertial and coriolis forces generated by the disk rotation can be employed for fluidic manipulation i.e., pumping [35], mixing [36,37], metering [38,39], decanting [40], calibrating [40], sample splitting [40], fluid separating [40] and valving [41]. Several biochemical operations have been implemented successfully on microfluidic compact disk such as biochemical analysis and immunoassay [42], detection of protein [43], fluorescence immunoassays [44], DNA extraction [45], nutrients determination in water [46], ELISA system [47,48] and foodborne pathogen detection [49].

Among several isothermal nucleic acid amplification techniques, LAMP is one of most established methods [50,51]. LAMP provides a secure reaction temperature range of $60-65{ }^{\circ} \mathrm{C}$ as compared to other low temperature methods, for example - Nucleic Acid Sequence-Based Amplification (NASBA), Helicase-Dependent Amplification (HDA), Strand Displacement Amplification (SDA) and so on - because in all these methods there is a risk that the reaction is initialized before the completion of the reaction preparation [50]. Therefore LAMP would be very beneficial as a POCT diagnostic device with its high sensitivity and specificity. In recent years, Ajima Muangchuen et al. [52] were able to develop a colorimetric endpoint detection technique based on DNA amplification by LAMP for Ehrlichia canis, Wu et al. [53] have developed an integrated glass microdevice for LAMP, Lee et al. [54] have developed an integrated micro-reactor system that is able to detect Hepatitis B virus (HBV) DNA using LAMP reaction, Feiwu Li et al. [55] have also developed a visual and rapid LAMP assay for detection of the $\operatorname{cry} 2 A b$ and $\operatorname{cry} 3 A$ genes in GM crops, these require either naked eye observation or UV-Visible Spectroscopy interfaced with a computer for obtaining confirmative results. Liang et al. [56] have reported a close-tube method using a wax-sealed fluorescent intercalator to detect LAMP product. Changchun Liu et al. [57] developed a single-chamber LAMP cassette to detect HIV-1 in oral fluid which requires a portable ESE optical detection system interfaced with a computer to get the confirmative results from generated graph. The developed system called micro-LAMP ( $\mu$ LAMP) by Fang et al. [58] required naked eye observation or compact real-time absorbance detection device for end-point detection which is expensive and complex system. Analyzing the current techniques for endpoint detection of LAMP reaction, it is necessary to develop an endpoint detection system which can provide automatic and digital confirmative results.

In this study, LAMP was performed in tubes with Bst DNA polymerase and a set of specially designed six primers which were incubated in $63{ }^{\circ} \mathrm{C}$ constant temperature for $60 \mathrm{~min}$, followed by enzyme inactivation at $80{ }^{\circ} \mathrm{C}$ for 2 min to complete the reaction. We developed a low cost portable system equipped with an ultraviolet (UV) emitter and a color sensor for the purpose of automation and digitization for the endpoint detection technique of LAMP amplicons. 


\section{Methodology}

The method to develop the endpoint detection system for the LAMP amplicons comprise of three primary steps, i.e., sample preparation, microfluidic disc fabrication and development of the detection system. Samples of LAMP amplicons with Salmonella bacteria were prepared following the tube-based method. Then a microfluidic CD featuring with detection chamber was fabricated. An electronic detection system was designed with suitable electronic components. The detection system was tested with LAMP amplicons containing different concentrations of Salmonella bacteria.

\subsection{Sample Preparation}

The LAMP amplicons were prepared according to protocols provide by Notomi et al. [59] using Loopamp DNA Amplification Kit (Eiken Chemical Co., Ltd., Tokyo, Japan). The LAMP reactions were carried out in a total volume of $25 \mu \mathrm{L} /$ test containing $12.5 \mu \mathrm{L}$ of $2 \mathrm{X}$ reaction mix composition ( $40 \mathrm{mM}$ Tris- $\mathrm{HCl}$ (pH8.8), $20 \mathrm{mM} \mathrm{KCI}, 16 \mathrm{mM} \mathrm{MgSO}_{4}, 20 \mathrm{mM}\left(\mathrm{NH}_{4}\right)_{2} \mathrm{SO}_{4}, 0.2 \%$ Tween20, $1.6 \mathrm{M}$ Betaine, $2.8 \mathrm{mM}$ each dNTPs) provided in the kit, 40 pmol of each inner primer FIP and BIP, 5 pmol of each primer F3 and B3, 20 pmol of each loop primer LF and LB, $8 \mathrm{U}$ of Bst DNA polymerase in volume of $1.0 \mu \mathrm{L}, 2.0 \mu \mathrm{L}$ of deionized water and $2.5 \mu \mathrm{L}$ of DNA template of Salmonella. The same reaction mixture without DNA template (replaced by deionized water) was used as a negative control. The primers were designed based on the fadA gene of Salmonella enterica Typhimurium (GenBank accession number NC003197.1) using the LAMP Primer Explorer V4 software [60]. The primer sequences are proprietary information. DNA extraction was done by direct cell lysate boiling method and DNA concentration was measured using the NanoDrop 2000 UV-Vis Spectrophotometer. The LAMP reactions were carried out in a heat block at $65{ }^{\circ} \mathrm{C}$ for $60 \mathrm{~min}$, followed by enzyme inactivation at $80{ }^{\circ} \mathrm{C}$ for $2 \mathrm{~min}$ to complete the reaction and then cooled off at $4{ }^{\circ} \mathrm{C}$. An aliquot of $1 \mu \mathrm{L}$ of 10 -fold diluted SYBR Green I dye was added to $25 \mu \mathrm{L}$ of amplicons of the LAMP assay. Immediately, the results could be visualized via the color change: a positive result is indicated by a color change from orange to yellowish green whilst in a negative result there is no change of color, i.e., orange.

\subsection{Disc Fabrication}

A microfluidic compact disk (CD) was designed using a computer aided design software (i.e., AutoCAD) and fabricated with layers of transparent thermoplastic of poly methyl methacrylate (PMMA) and a custom manufactured pressure sensitive adhesive (PSA). The CD composed of three layers where two layers of PMMA were bounded with a layer of PSA. Computer numerical control (CNC) machine and digitally controlled cutting plotter machine were utilized to cut the microfluidic features (chambers) in the PMMA and PSA layer, respectively. The chambers were engraved in a $4 \mathrm{~mm}$ thick PMMA layer (bottom layer) to load $26 \mu \mathrm{L}$ volume of liquid. Inlets/outlets holes were cut-out in a $2 \mathrm{~mm}$ PMMA layer (top layer) with a shape of interrupting edge. Then the three layers were aligned and pressed-bound together using a custom made press-roller system (Figure 1). 


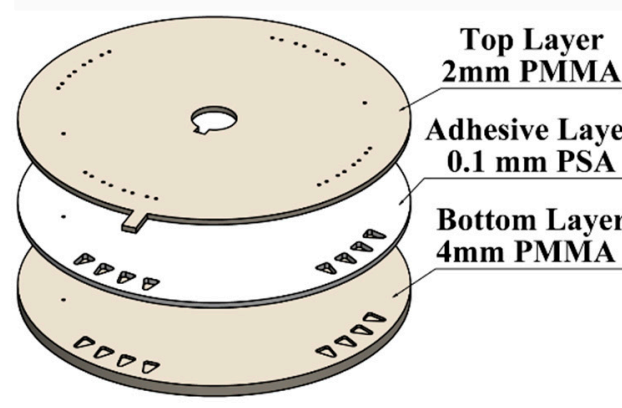

Top-Corner View

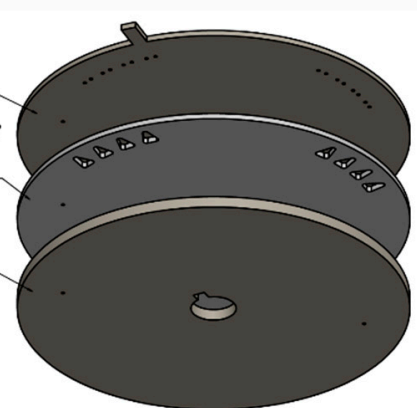

Bottom-Corner View

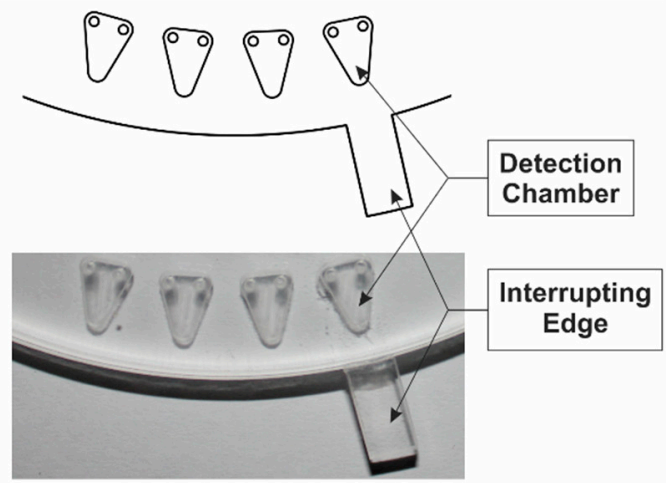

(B)

Figure 1. Microfluidic CD (A) 3D expanded view; (B) Top view of the featuring section.

\subsection{Development of the Endpoint Detection System for LAMP}

\subsubsection{Design of Detection System}

The development of the detection system includes: designing of an electronic circuit with suitable electronic components, designing and fabricating a mechanical structure, and developing control program for microcontroller to control and process the whole sequence. The system comprised of several electronic components: a hybrid type stepping motor driven by a motor driver, photointerrupter for accurate positioning the microfluidic CD on target location, a UV emitter ( $365 \mathrm{~nm}$ peak) driven with a LED driver to excite the dye of LAMP amplicons in the detection chamber, a UV filter (optical grade UV glass substrate) to reduce unwanted UV light after excitation of target sample and a color sensor (which includes four groups of photodiode with different color filter, i.e., red, green, blue and clear; Manufacture Part No: TCS3200) to convert the color light intensity to electric pulse train with different frequency levels. A microcontroller (ATmega328) was used for controlling the stepper motor rotation, functioning photointerrupter, processing the color sensor output, and recording the data and displaying the detection result with LCD. The block diagram of the endpoint detection system is shown in Figure 2. Mechanical structure of the system was fabricated with an optical noiseless design using opaque black thermoplastic (i.e., PMMA) (Figure 3). The structure has a sensor holder which houses a UV emitter, a color sensor and a UV filter aligning with the same axis (Figure 4).

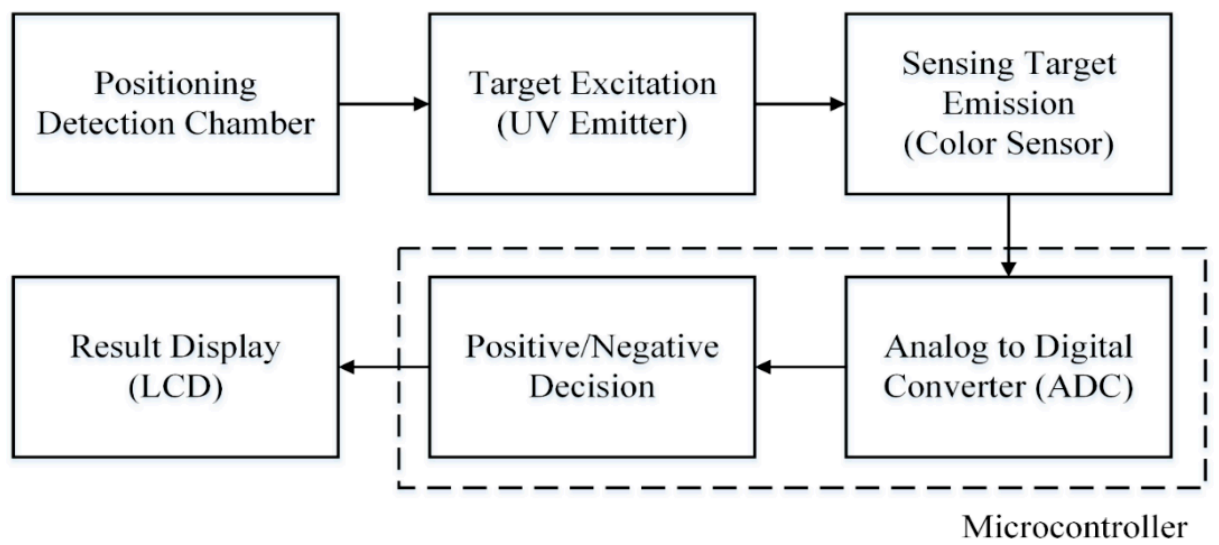

Figure 2. Block diagram of the endpoint detection system. 


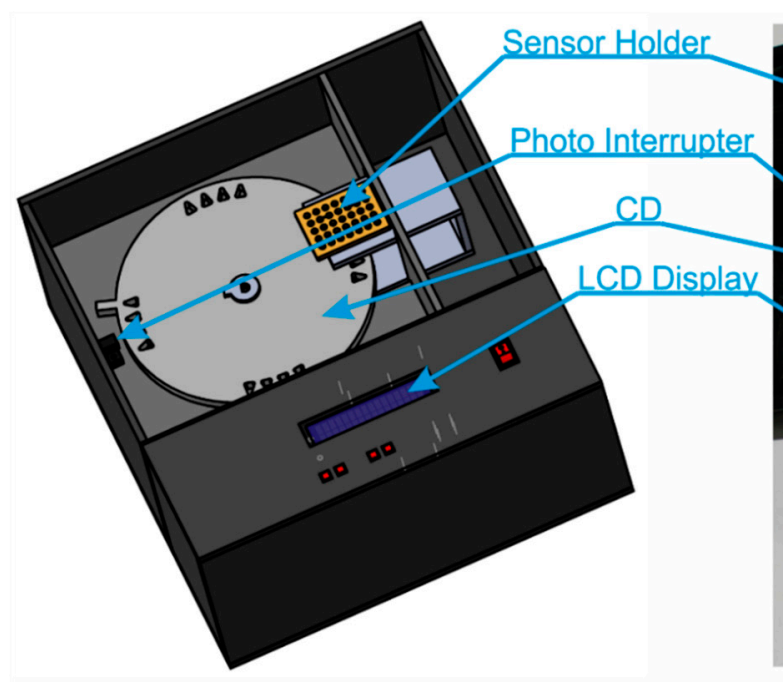

(A)

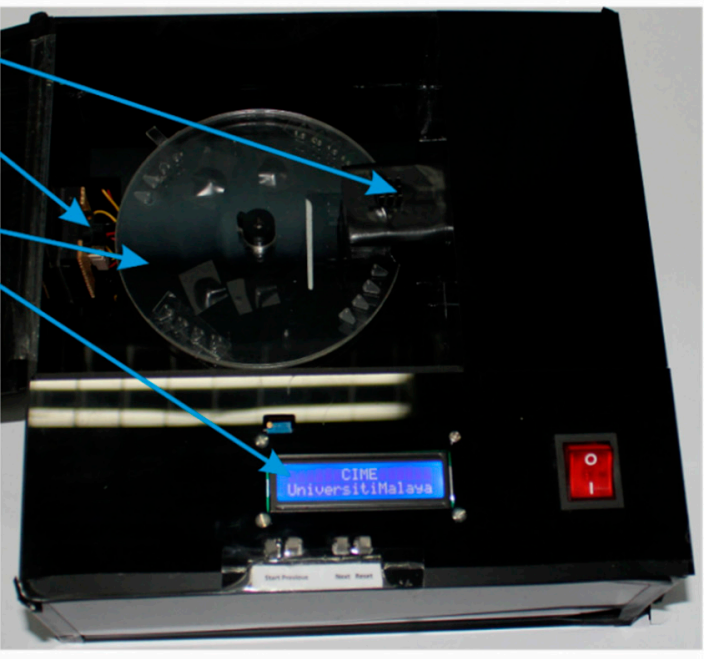

(B)

Figure 3. Endpoint detection system (A) Schematic illustration in 3D; (B) Photograph of the operating model.

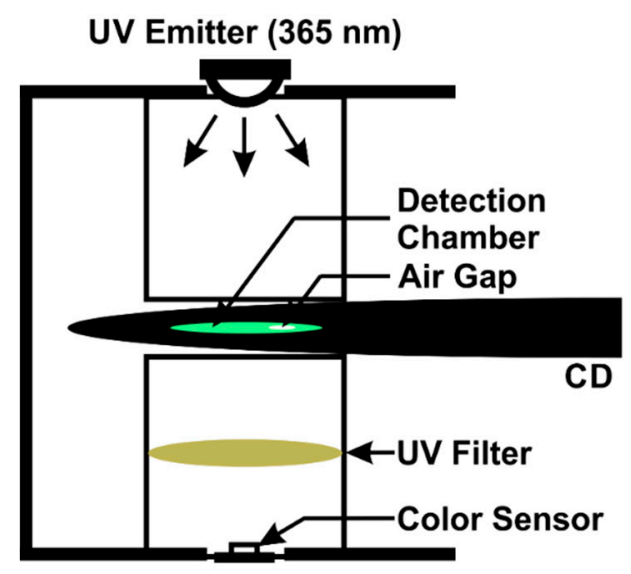

(A)

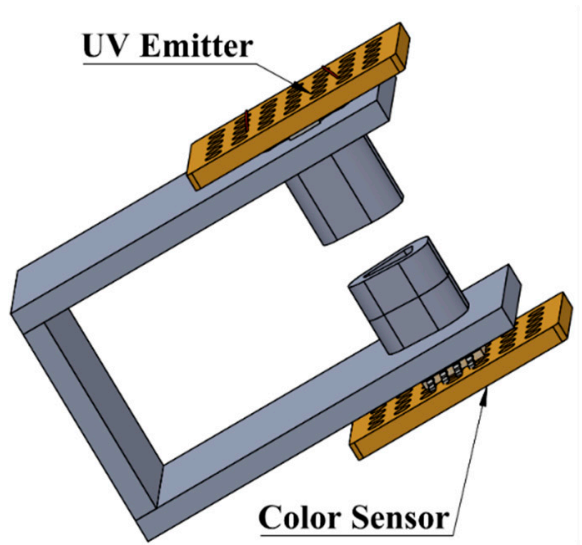

(B)

Figure 4. Sensor holder (A) Schematic illustration in 2D; (B) Schematic illustration in 3D.

\subsubsection{Operation of Detection System}

The detection chamber of the microfluidic CD was pre-loaded with the resulting dye of LAMP amplicons and SYBR Green I and then placed on the detection system. On pressing the start button of the system, the CD rotates anti-clockwise until the first chamber is being placed in alignment with the same axis of the UV emitter and color sensor. Then the UV emitter and color sensor are enabled. To process the color sensor output, the microcontroller calculates the mean of 15 continuous pulse durations (due to achieve stable pulse duration reading) from the sensor as single sensor reading for one target. By comparing the sensor reading level with the predefined decision rule for LAMP amplicons detection, a "Positive" or "Negative" text is displayed on the LCD display. Then the motor rotates until the second detection chamber is aligned with the UV emitter and color sensor. Using exactly the same steps, the sensor reads the light intensity level and displays the detection result simultaneously. These steps are 
being repeated for each of the sixteen detection chambers sequentially. After reading all the samples, the results can be reviewed on the LCD display using navigation keys.

\section{Results and Discussion}

An Epoch Microplate Spectrophotometer and Synergy H1 Hybrid Multi-Mode Microplate Reader were utilized to detect absorbance and fluorescence of the resulting dye of LAMP amplicons with SYBR Green I, respectively. Figure 5 shows the resulting dye absorbs UV light $\left(\lambda_{\max }=262 \mathrm{~nm}\right)$ and emits green light $\left(\lambda_{\max }=524 \mathrm{~nm}\right)$. A UV emitter of $365 \mathrm{~nm}$ peak wavelength was utilized for excitation of LAMP amplicons rather than $262 \mathrm{~nm}$ because of the cost and availability of the component. Moreover, the level of excitation from LAMP amplicons using $365 \mathrm{~nm}$ UV emitter is detectable using the color sensor. The group of green photodiodes in color sensor was enabled, because its relative spectral sensitivity is more suitable with the emission spectrum of LAMP amplicons dye as compare to other groups of photodiodes.

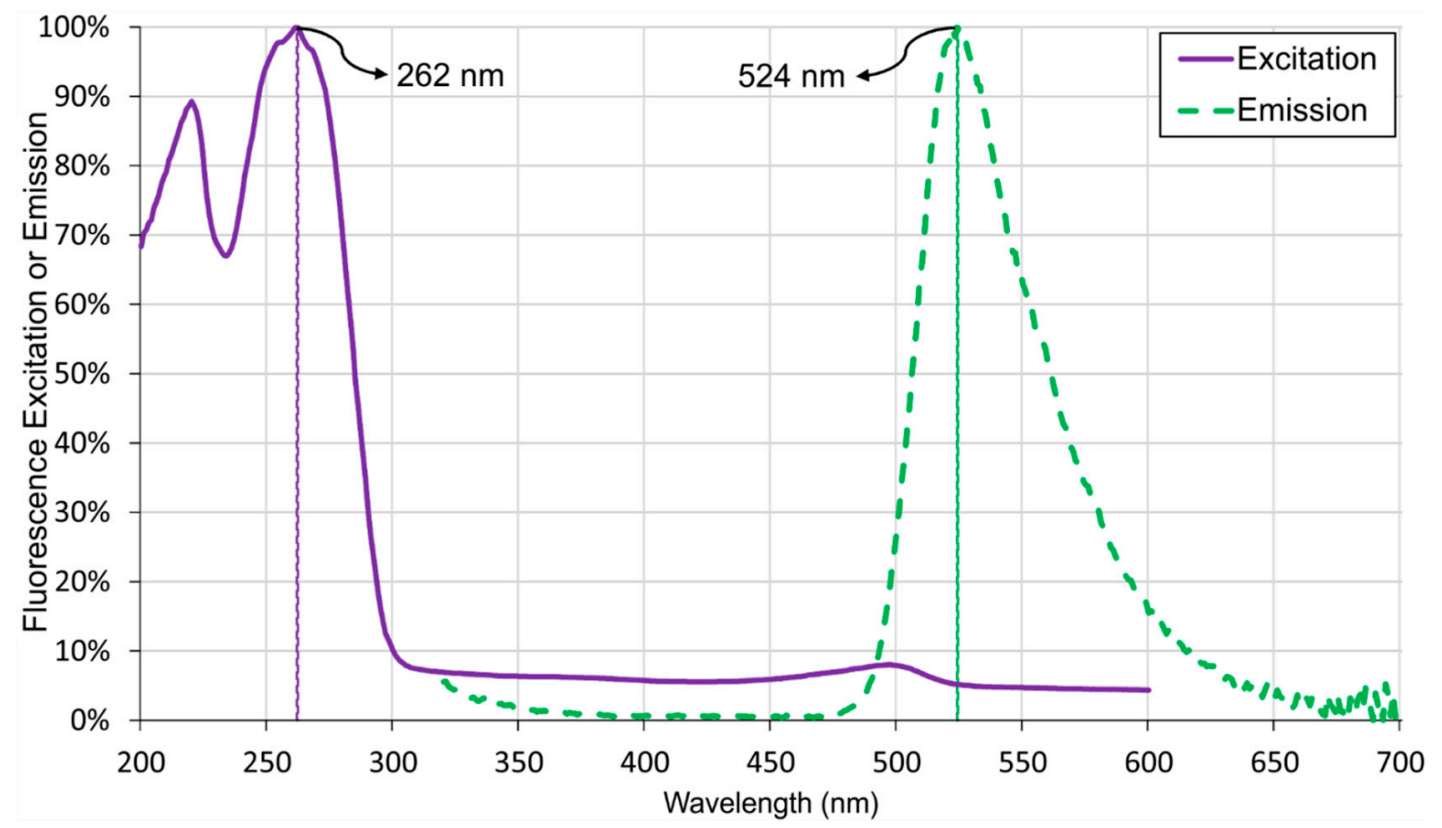

Figure 5. Spectrogram of LAMP Amplicons with Salmonella bacteria.

A total of seven LAMP reactions were performed with seven different concentrations of DNA templates (10-fold serial dilutions from $2.5 \times 10^{0} \mathrm{ng} / \mu \mathrm{L}$ to $2.5 \times 10^{-6} \mathrm{ng} / \mu \mathrm{L}$ ) of Salmonella bacteria and one reaction with deionized water (DW) as a negative control (Figure 6A) and then the dye was transferred in the detection chamber of microfluidic $\mathrm{CD}$ (Figure 6B). According to Figure 6A, the initial orange color of SYBR Green I changed to yellowish green in tube number 1 to 4 (positive result), the color turned to faded orange in tube number 5 to 7 (negative result) and the orange color remained unchanged for tube number 8 (negative result). These results indicate the lower limit of detection is $2.5 \times 10^{-3} \mathrm{ng} / \mu \mathrm{L}$ for the DNA of Salmonella bacteria. As the LAMP detection with SYBR Green I is a qualitative detection process, it gives same intensity of color visually for either positive or negative results. Table 1 and Figure 7 show the sensitivity test results of the detection system when the resulting dye is loaded in the microfluidic CD. The processed sensor output value (pulse duration) as described in the methodology section was normalized with feature scaling method. Table 1 and Figure 7 also illustrate 
the mean sensor readings with the standard deviation obtained for three different sets of data. These results indicate the normalized value range of sensor output was less than 0.1 (green triangle markers) for the positive control and higher than 0.8 (orange circle markers) for the negative control. As the frequency of sensor output pulse train is proportional to the incident light intensity on the sensor surface and the sensor was operated in green filter mode, which caused higher output pulse frequency and lower output pulse duration for positive control than negative control.

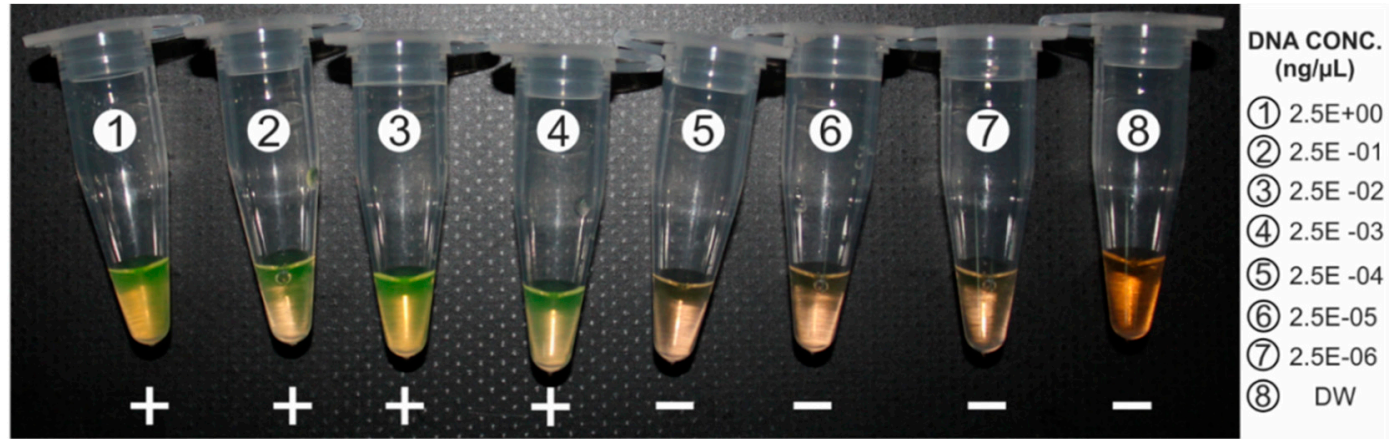

(A)

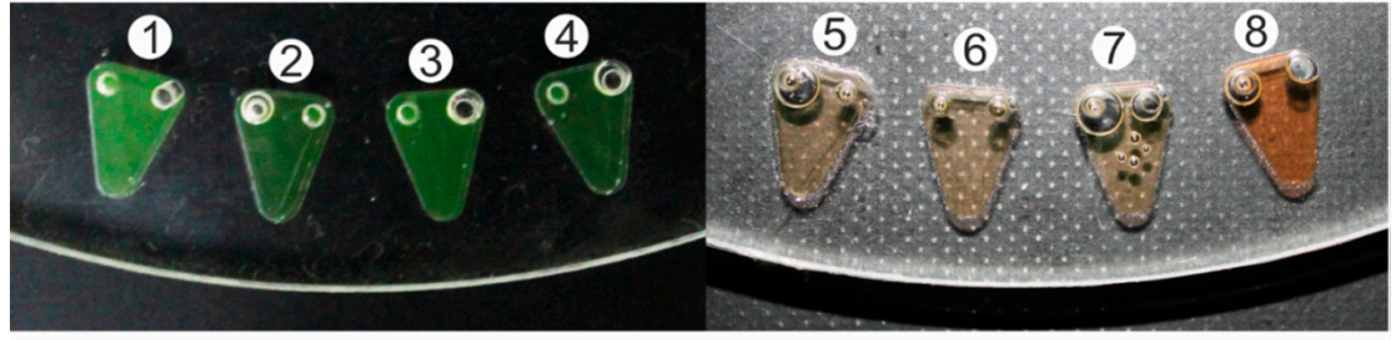

(B)

Figure 6. Naked-eye inspection (A) Resulting dye (26 $\mu \mathrm{L})$ of LAMP amplicons ( $25 \mu \mathrm{L})$ and SYBR Green I $(1 \mu \mathrm{L})$ in ambient light. (B) Microfluidic CD loaded with the resulting dye.

Table 1. Sensitivity test results of the endpoint detection system at different concentration of Salmonella DNA template.

\begin{tabular}{cccccc}
\hline $\begin{array}{c}\text { Sample } \\
\text { ID }\end{array}$ & $\begin{array}{c}\text { Concentration of } \\
\text { DNA Template } \\
(\mathbf{n g} / \boldsymbol{\mu L} \text { ) for } \\
\text { LAMP Reaction }\end{array}$ & $\begin{array}{c}\text { Color Changes of } \\
\text { Resulting Dye } * *\end{array}$ & $\begin{array}{c}\text { Visual } \\
\text { Identification } \\
\text { of Resulting } \\
\text { Dye ** }\end{array}$ & $\begin{array}{c}\text { Sensor Reading } \\
\text { (Normalized } \\
\text { Pulse Duration) } \\
\text { Mean } \pm \text { SD }\end{array}$ & $\begin{array}{c}\text { Automatic } \\
\text { Detection System } \\
\text { Interpretation of } \\
\text { Resulting Dye ** }\end{array}$ \\
\hline 1 & $2.5 \mathrm{E}+00$ & Yellowish Green & Positive & $0.067 \pm 0.038$ & Positive \\
2 & $2.5 \mathrm{E}-01$ & Yellowish Green & Positive & $0.025 \pm 0.035$ & Positive \\
3 & $2.5 \mathrm{E}-02$ & Yellowish Green & Positive & $0.045 \pm 0.043$ & Positive \\
4 & $2.5 \mathrm{E}-03$ & Yellowish Green & Positive & $0.065 \pm 0.033$ & Positive \\
5 & $2.5 \mathrm{E}-04$ & Faded Orange & Negative & $0.834 \pm 0.042$ & Negative \\
6 & $2.5 \mathrm{E}-05$ & Faded Orange & Negative & $0.832 \pm 0.035$ & Negative \\
7 & $2.5 \mathrm{E}-06$ & Faded Orange & Negative & $0.820 \pm 0.037$ & Negative \\
8 & $0 *$ & Unchanged & Negative & $0.971 \pm 0.037$ & Negative \\
\hline$* *$ resulting dye is the dye of LAMP amplicons and SYBR Green I; $*$ DNA template is replaced with DW; SD,
\end{tabular}




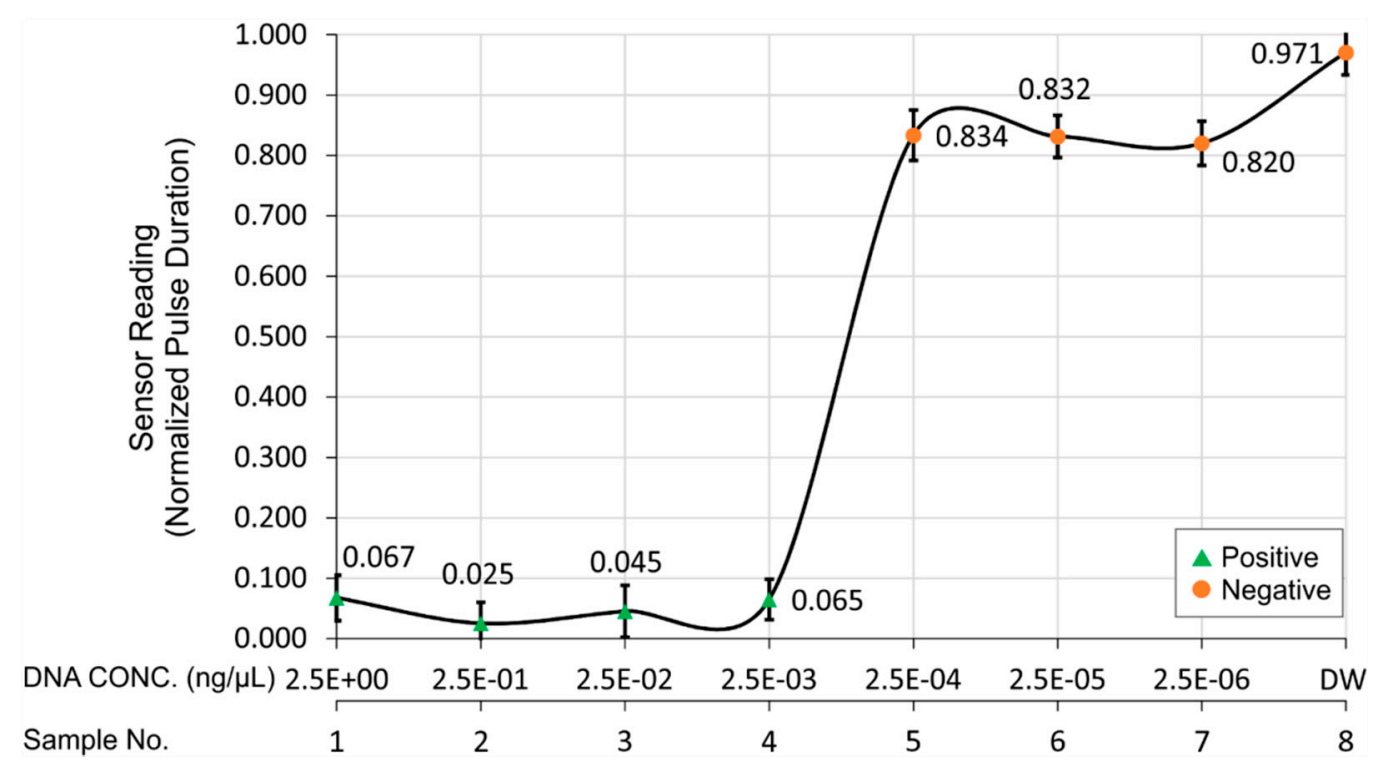

Figure 7. Sensitivity test results of the detection system with different concentrations of Salmonella DNA template. The target is classified as positive when the sensor reading is lower than 0.1 and as negative when the sensor reading is higher than 0.8 .

As a parallel assessment, sensitivity test of LAMP assay and PCR assay were tested using 10-fold serial dilutions of pure Salmonella cultured DNA. The PCR can detect up to $3.4 \times 10^{6} \mathrm{CFU} / \mathrm{mL}$ of pure Salmonella culture. The detection limit of LAMP on the same set of serially diluted culture was $3.4 \times 10^{4} \mathrm{CFU} / \mathrm{mL}$ which is 100 times more sensitive than conventional PCR.

Analyzing the sensitivity test results of the detection system with different concentrations of Salmonella bacteria DNA, the developed detection system can detect the LAMP amplicons successfully. The current endpoint detection techniques of LAMP amplicons are color changes observation of fluorescent dye with naked eye $[52,53,55,56,58]$ or spectrometer $[52,54]$, accumulated white pellet visualization with turbidimeter after a brief centrifugation of LAMP amplicons [55] and agarose gel electrophoresis showing ladder of DNA bands [58,61]. These methods take $2-5 \mathrm{~min}$ or more (depends on the number of LAMP reactions performed) to perform and require presence of personnel to make a confirmative decision (positive or negative). On other hand, this developed detection system can detect 16 samples of LAMP amplicons within $6 \mathrm{~s}$ automatically with one hundred percent accuracy. The detection results could be transferred from the detection system to a smart phone and remote places sequentially to improve the contamination monitoring and response time. The developed detection system has succeeded in improving the endpoint detection of LAMP amplicons in terms of time and labor. Moreover, the estimated manufacturing cost of the detection system is less than USD 160 which can be considered as low cost compared to existing detection techniques.

\section{Conclusions}

A color light intensity detection system for LAMP amplicons was designed, implemented and tested for the purpose of automation on a microfluidic CD platform. The developed system could interpret and detect the LAMP amplicons automatically in terms of positive or negative results. The sensitivity test of detection system was performed and detection limit of $2.5 \times 10^{-3} \mathrm{ng} / \mu \mathrm{L}$ of Salmonella DNA was 
observed. It could accurately differentiate the positive results from the negative ones. In addition, it could process the sensor reading and display the detection results for 16 samples within $6 \mathrm{~s}$. This detection system enhances the convenience in visualizing the endpoint result as compared to the current naked-eye observation method for LAMP amplicons. This system would be suitable as a point-of-care diagnosis device for rapid detection of foodborne pathogens due to its portability and low manufacturing cost.

\section{Acknowledgments}

This research is financially supported by University of Malaya (UM) research grant, UM Research Collaborative Grant Scheme (Project No: CG003-2013), MOSTI Science Fund (Project No: GA013-2013). We would like to thank Karunan Joseph from Department of Biomedical Engineering, Faculty of Engineering, University of Malaya for the assistance during experimental design and Lee Huikey from Microbiology Unit, Institute of Biological Sciences, Faculty of Science, University of Malaya for the assistance during the sample preparation. Fatimah Ibrahim would like to acknowledge Yayasan Sultan Iskandar Johor Foundation for funding the Special Equipment Grant.

\section{Author Contributions}

In this paper, F.I., K.L.T. and S.M.U. conceived the experiment; S.M.U., J.C., K.L.T. and F.I. designed the experiment; S.M.U., A.A.S., A.T. and K.X.P. performed the experiment; S.M.U., J.C., K.L.T. and F.I. analyzed the data; F.I., K.L.T. contributed reagents/materials/analysis tools; S.M.U wrote the paper; F.I., K.L.T., U.H., M.S.M. and J.C. improved, analyzed and proof read the manuscript.

\section{Conflicts of Interest}

The authors declare no conflict of interest.

\section{References}

1. Crim, S.M.; Iwamoto, M.; Huang, J.Y.; Griffin, P.M.; Gilliss, D.; Cronquist, A.B.; Cartter, M.; Tobin-D’Angelo, M.; Blythe, D.; Smith, K. Incidence and trends of infection with pathogens transmitted commonly through food-foodborne diseases active surveillance network, 10 us sites, 2006-2013. Morb. Mortal. Wkly. Rep. 2014, 63, 328-332.

2. Mandal, P.; Biswas, A.; Choi, K.; Pal, U. Methods for rapid detection of foodborne pathogens: An overview. Am. J. Food Technol. 2011, 6, 87-102.

3. Velusamy, V.; Arshak, K.; Korostynska, O.; Oliwa, K.; Adley, C. An overview of foodborne pathogen detection: In the perspective of biosensors. Biotechnol. Adv. 2010, 28, 232-254.

4. Jofré, A.; Martin, B.; Garriga, M.; Hugas, M.; Pla, M.; Rodríguez-Lázaro, D.; Aymerich, T. Simultaneous detection of Listeria monocytogenes and Salmonella by multiplex PCR in cooked ham. Food Microbiol. 2005, 22, 109-115.

5. Ko, S.; Grant, S.A. A novel fret-based optical fiber biosensor for rapid detection of Salmonella Typhimurium. Biosens. Bioelectron. 2006, 21, 1283-1290. 
6. Bhunia, A.K. Biosensors and bio-based methods for the separation and detection of foodborne pathogens. Adv. Food Nutr. Res. 2008, 54, 1-44.

7. Rasooly, A.; Herold, K.E. Biosensors for the analysis of food-and waterborne pathogens and their toxins. J. AOAC Int. 2006, 89, 873-883.

8. Leonard, P.; Hearty, S.; Quinn, J.; O'Kennedy, R. A generic approach for the detection of whole Listeria Monocytogenes cells in contaminated samples using surface plasmon resonance. Biosens. Bioelectron. 2004, 19, 1331-1335.

9. Warsinke, A.; Benkert, A.; Scheller, F. Electrochemical immunoassays. Fresenius J. Anal. Chem. 2000, 366, 622-634.

10. Ko, S.; Grant, S.A. Development of a novel fret method for detection of Listeria or Salmonella. Sens. Actuators B Chem. 2003, 96, 372-378.

11. Majoul, I. Analysing the action of bacterial toxins in living cells with fluorescence resonance energy transfer (fret). Int. J. Med. Microbiol. 2004, 293, 495-503.

12. Bruno, J.G.; Ulvick, S.J.; Uzzell, G.L.; Tabb, J.S.; Valdes, E.R.; Batt, C.A. Novel immuno-fret assay method for Bacillus spores and Escherichia coli O157: H7. Biochem. Biophys. Res. Commun. 2001, 287, 875-880.

13. O'sullivan, C.; Vaughan, R.; Guilbault, G. Piezoelectric Immunosensors-Theory and Applications; Taylor \& Francis: Cork, Ireland, 1999.

14. Pancrazio, J.; Whelan, J.; Borkholder, D.; Ma, W.; Stenger, D. Development and application of cell-based biosensors. Ann. Biomed. Eng. 1999, 27, 697-711.

15. Bhunia, A.K.; Wampler, J.L. Animal and cell culture models for foodborne bacterial pathogens. Foodborne Pathog. Microbiol. Mol. Biol. 2005, 15-32.

16. Ziegler, C. Cell-based biosensors. Fresenius' J. Anal. Chem. 2000, 366, 552-559.

17. Wang, R.F.; Cao, W.W.; Cerniglia, C. A universal protocol for PCR detection of 13 species of foodborne pathogens in foods. J. Appl. Microbiol. 1997, 83, 727-736.

18. Jeníková, G.; Pazlarová, J.; Demnerová, K. Detection of Salmonella in food samples by the combination of immunomagnetic separation and pcr assay. Int. Microbiol. 2010, 3, 225-229.

19. Oliveira, S.; Santos, L.; Schuch, D.; Silva, A.; Salle, C.; Canal, C. Detection and identification of Salmonellas from poultry-related samples by PCR. Vet. Microbiol. 2002, 87, 25-35.

20. Malorny, B.; Paccassoni, E.; Fach, P.; Bunge, C.; Martin, A.; Helmuth, R. Diagnostic real-time pcr for detection of Salmonella in food. Appl. Environ. Microbiol. 2004, 70, 7046-7052.

21. Beckers, H.; Tips, P.; Soentoro, P.; Delfgou-Van Asch, E.; Peters, R. The efficacy of enzyme immunoassays for the detection of Salmonellas. Food Microbiol. 1988, 5, 147-156.

22. Magliulo, M.; Simoni, P.; Guardigli, M.; Michelini, E.; Luciani, M.; Lelli, R.; Roda, A. A rapid multiplexed chemiluminescent immunoassay for the detection of Escherichia coli O157:H7, Yersinia Enterocolitica, Salmonella Typhimurium, and Listeria Monocytogenes pathogen bacteria. J. Agric. Food Chem. 2007, 55, 4933-4939.

23. Chapman, P.; Malo, A.; Siddons, C.; Harkin, M. Use of commercial enzyme immunoassays and immunomagnetic separation systems for detecting Escherichia coli $\mathrm{O} 157$ in bovine fecal samples. Appl. Environ. Microbiol. 1997, 63, 2549-2553.

24. Rasooly, A.; Herold, K.E. Food microbial pathogen detection and analysis using DNA microarray technologies. Foodborne Pathog. Dis. 2008, 5, 531-550. 
25. Haeberle, S.; Zengerle, R. Microfluidic platforms for lab-on-a-chip applications. Lab Chip 2007, 7, 1094-1110.

26. Sia, S.K.; Kricka, L.J. Microfluidics and point-of-care testing. Lab Chip 2008, 8, 1982-1983.

27. Mairhofer, J.; Roppert, K.; Ertl, P. Microfluidic systems for pathogen sensing: A review. Sensors 2009, 9, 4804-4823.

28. Lagally, E.; Scherer, J.; Blazej, R.; Toriello, N.; Diep, B.; Ramchandani, M.; Sensabaugh, G.; Riley, L.; Mathies, R. Integrated portable genetic analysis microsystem for pathogen/infectious disease detection. Anal. Chem. 2004, 76, 3162-3170.

29. Easley, C.J.; Karlinsey, J.M.; Bienvenue, J.M.; Legendre, L.A.; Roper, M.G.; Feldman, S.H.; Hughes, M.A.; Hewlett, E.L.; Merkel, T.J.; Ferrance, J.P. A fully integrated microfluidic genetic analysis system with sample-in-answer-out capability. Proc. Natl. Acad. Sci. USA 2006, 103, 19272-19277.

30. Beyor, N.; Yi, L.; Seo, T.S.; Mathies, R.A. Integrated capture, concentration, polymerase chain reaction, and capillary electrophoretic analysis of pathogens on a chip. Anal. Chem. 2009, 81, $3523-3528$.

31. Dharmasiri, U.; Witek, M.A.; Adams, A.A.; Osiri, J.K.; Hupert, M.L.; Bianchi, T.S.; Roelke, D.L.; Soper, S.A. Enrichment and detection of Escherichia coli O157:H7 from water samples using an antibody modified microfluidic chip. Anal. Chem. 2010, 82, 2844-2849.

32. Chen, Y.-W.; Wang, H.; Hupert, M.; Witek, M.; Dharmasiri, U.; Pingle, M.R.; Barany, F.; Soper, S.A. Modular microfluidic system fabricated in thermoplastics for the strain-specific detection of bacterial pathogens. Lab Chip 2012, 12, 3348-3355.

33. Madou, M.; Zoval, J.; Jia, G.; Kido, H.; Kim, J.; Kim, N. Lab on a cd. Annu. Rev. Biomed. Eng. 2006, 8, 601-628.

34. Gorkin, R.; Park, J.; Siegrist, J.; Amasia, M.; Lee, B.S.; Park, J.-M.; Kim, J.; Kim, H.; Madou, M.; Cho, Y.-K. Centrifugal microfluidics for biomedical applications. Lab Chip 2010, 10, 1758-1773.

35. Zoval, J.V.; Madou, M.J. Centrifuge-based fluidic platforms. IEEE Proc. 2004, 92, 140-153.

36. Grumann, M.; Geipel, A.; Riegger, L.; Zengerle, R.; Ducrée, J. Batch-mode mixing on centrifugal microfluidic platforms. Lab Chip 2005, 5, 560-565.

37. Haeberle, S.; Brenner, T.; Schlosser, H.P.; Zengerle, R.; Ducrée, J. Centrifugal micromixery. Chem. Eng. Technol. 2005, 28, 613-616.

38. Park, J.-M.; Cho, Y.-K.; Lee, B.-S.; Lee, J.-G.; Ko, C. Multifunctional microvalves control by optical illumination on nanoheaters and its application in centrifugal microfluidic devices. Lab Chip 2007, 7, 557-564.

39. Steigert, J.; Grumann, M.; Brenner, T.; Riegger, L.; Harter, J.; Zengerle, R.; Ducrée, J. Fully integrated whole blood testing by real-time absorption measurement on a centrifugal platform. Lab Chip 2006, 6, 1040-1044.

40. Martinez-Duarte, R.; Gorkin, R.A., III; Abi-Samra, K.; Madou, M.J. The integration of 3d carbon-electrode dielectrophoresis on a cd-like centrifugal microfluidic platform. Lab Chip 2010, 10, 1030-1043.

41. Ducrée, J.; Haeberle, S.; Lutz, S.; Pausch, S.; Von Stetten, F.; Zengerle, R. The centrifugal microfluidic bio-disk platform. J. Micromech. Microeng. 2007, 17, S103-S115. 
42. Lee, B.S.; Lee, Y.U.; Kim, H.-S.; Kim, T.-H.; Park, J.; Lee, J.-G.; Kim, J.; Kim, H.; Lee, W.G.; Cho, Y.-K. Fully integrated lab-on-a-disc for simultaneous analysis of biochemistry and immunoassay from whole blood. Lab Chip 2011, 11, 70-78.

43. Park, J.; Sunkara, V.; Kim, T.-H.; Hwang, H.; Cho, Y.-K. Lab-on-a-disc for fully integrated multiplex immunoassays. Anal. Chem. 2012, 84, 2133-2140.

44. Riegger, L.; Grumann, M.; Nann, T.; Riegler, J.; Ehlert, O.; Bessler, W.; Mittenbuehler, K.; Urban, G.; Pastewka, L.; Brenner, T. Read-out concepts for multiplexed bead-based fluorescence immunoassays on centrifugal microfluidic platforms. Sens. Actuators A Phys. 2006, 126, 455-462.

45. Cho, Y.-K.; Lee, J.-G.; Park, J.-M.; Lee, B.-S.; Lee, Y.; Ko, C. One-step pathogen specific DNA extraction from whole blood on a centrifugal microfluidic device. Lab Chip 2007, 7, 565-573.

46. Hwang, H.; Kim, Y.; Cho, J.; Lee, J.-Y.; Choi, M.-S.; Cho, Y.-K. Lab-on-a-disc for simultaneous determination of nutrients in water. Anal. Chem. 2013, 85, 2954-2960.

47. Lee, B.S.; Lee, J.-N.; Park, J.-M.; Lee, J.-G.; Kim, S.; Cho, Y.-K.; Ko, C. A fully automated immunoassay from whole blood on a disc. Lab Chip 2009, 9, 1548-1555.

48. Lai, S.; Wang, S.; Luo, J.; Lee, L.J.; Yang, S.-T.; Madou, M.J. Design of a compact disk-like microfluidic platform for enzyme-linked immunosorbent assay. Anal. Chem. 2004, 76, 1832-1837.

49. Kim, T.-H.; Park, J.; Kim, C.-J.; Cho, Y.-K. Fully integrated lab-on-a-disc for nucleic acid analysis of food-borne pathogens. Anal. Chem. 2014, 86, 3841-3848.

50. Niemz, A.; Ferguson, T.M.; Boyle, D.S. Point-of-care nucleic acid testing for infectious diseases. Trends Biotechnol. 2011, 29, 240-250.

51. Chang, C.-C.; Chen, C.-C.; Wei, S.-C.; Lu, H.-H.; Liang, Y.-H.; Lin, C.-W. Diagnostic devices for isothermal nucleic acid amplification. Sensors 2012, 12, 8319-8337.

52. Muangchuen, A.; Chaumpluk, P.; Suriyasomboon, A.; Ekgasit, S. Colorimetric detection of ehrlichia canis via nucleic acid hybridization in gold nano-colloids. Sensors 2014, 14, 14472-14487.

53. Wu, Q.; Jin, W.; Zhou, C.; Han, S.; Yang, W.; Zhu, Q.; Jin, Q.; Mu, Y. Integrated glass microdevice for nucleic acid purification, loop-mediated isothermal amplification, and online detection. Anal. Chem. 2011, 83, 3336-3342.

54. Lee, S.-Y.; Lee, C.-N.; Mark, H.; Meldrum, D.R.; Lin, C.-W. Efficient, specific, compact Hepatitis $\mathrm{b}$ diagnostic device: Optical detection of the Hepatitis $\mathrm{b}$ virus by isothermal amplification. Sens. Actuators B Chem. 2007, 127, 598-605.

55. Li, F.; Yan, W.; Long, L.; Qi, X.; Li, C.; Zhang, S. Development and application of loop-mediated isothermal amplification assays for rapid visual detection of cry2 $\mathrm{Ab}$ and cry3 $\mathrm{A}$ genes in genetically-modified crops. Int. J. Mol. Sci. 2014, 15, 15109-15121.

56. Liang, C.; Cheng, S.; Chu, Y.; Wu, H.; Zou, B.; Huang, H.; Xi, T.; Zhou, G. A closed-tube detection of loop-mediated isothermal amplification (lamp) products using a wax-sealed fluorescent intercalator. J. Nanosci. Nanotechnol. 2013, 13, 3999-4005.

57. Liu, C.; Geva, E.; Mauk, M.; Qiu, X.; Abrams, W.R.; Malamud, D.; Curtis, K.; Owen, S.M.; Bau, H.H. An isothermal amplification reactor with an integrated isolation membrane for point-of-care detection of infectious diseases. Analyst 2011, 136, 2069-2076.

58. Fang, X.; Liu, Y.; Kong, J.; Jiang, X. Loop-mediated isothermal amplification integrated on microfluidic chips for point-of-care quantitative detection of pathogens. Anal. Chem. 2010, 82, 3002-3006. 
59. Notomi, T.; Okayama, H.; Masubuchi, H.; Yonekawa, T.; Watanabe, K.; Amino, N.; Hase, T. Loop-mediated isothermal amplification of DNA. Nucleic Acids Res. 2000, 28, doi: 10.1093/ nar/28.12.e63

60. Primerexplore v4. Available online: http://primerexplorer.jp/elamp4.0.0/index.html (accessed on 13 November 2014).

61. Arunrut, N.; Prombun, P.; Saksmerprome, V.; Flegel, T.W.; Kiatpathomchai, W. Rapid and sensitive detection of infectious hypodermal and hematopoietic necrosis virus by loop-mediated isothermal amplification combined with a lateral flow dipstick. J. Virol. Methods 2011, 171, $21-25$.

(C) 2015 by the authors; licensee MDPI, Basel, Switzerland. This article is an open access article distributed under the terms and conditions of the Creative Commons Attribution license (http://creativecommons.org/licenses/by/4.0/). 